\title{
Effects of Various Temperatures and pH Values on the Extraction Yield of Phenolics from Litchi Fruit Pericarp Tissue and the Antioxidant Activity of the Extracted Anthocyanins
}

Neungnapa Ruenroengklin ${ }^{1, \#, ~ J i a ~ Z h o n g ~}{ }^{1, \#}$, Xuewu Duan ${ }^{1}$, Bao Yang ${ }^{1}$, Jianrong Li $^{2}$ and Yueming Jiang 1, 2,*

1 South China Botanical Garden, Chinese Academy of Sciences, Guangzhou 510650, P.R. China

2 College of Food Science and Biotechnology and Environmental Engineering, Zhejiang Gongshang University, Hangzhou, 310035, P.R. China

\# These authors equally contributed to this work.

* Author to whom correspondence should be addressed; E-mail: ymjiang@scbg.ac.cn; Tel.: +86 20 37252525; Fax: +862037252831

Received: 7 April 2008; in revised form: 27 June 2008 / Accepted: 27 June 2008 / Published: 22 July 2008

\begin{abstract}
Litchi fruit pericarp tissue is considered an important source of dietary phenolics. This study consisted of two experiments. The first was conducted to examine the effects of various extraction temperatures $\left(30,40,50,60,70\right.$ and $\left.80{ }^{\circ} \mathrm{C}\right)$ and $\mathrm{pH}$ values $(2,3,4,5$ and 6$)$ on the extraction yield of phenolics from litchi fruit pericarp. Extraction was most efficient at $\mathrm{pH} 4.0$, while an extraction temperature of $60^{\circ} \mathrm{C}$ was the best in terms of the combined extraction yield of phenolics and the stability of the extracted litchi anthocyanins. The second experiment was carried out to further evaluate the effects of various temperatures $\left(25,35,45,55\right.$ and $\left.65^{\circ} \mathrm{C}\right)$ and $\mathrm{pH}$ values $(1,3,5$ and 7$)$ on the total antioxidant ability and scavenging activities of DPPH radicals, hydroxyl radical and superoxide anion of the extracted anthocyanins. The results indicated that use of $45-60{ }^{\circ} \mathrm{C}$ or $\mathrm{pH}$ 3-4 exhibited a relatively high antioxidant activity. The study will help improve extraction yield of phenolics from litchi fruit pericarp and promote better utilization of the extracted litchi anthocyanins as antioxidants.
\end{abstract}

Keywords: Litchi, extraction, temperature, $\mathrm{pH}$, phenolics, anthocyanin, antioxidant activity 


\section{Introduction}

Litchi (Litchi chinensis Sonn.) is a subtropical fruit that originated in South-East Asia [1]. In recent years, litchi production has increased steadily around the world. Litchi fruit pericarp (LFP) accounts for approximately $15 \%$ by weight of the whole fresh fruit [2] and contains significant amounts of phenolics, among which anthocyanins are the major polyphenols. Anthocyanins play an important pharmacological role against various human diseases, such as cardiovascular disease, cancer, inflammation and allergies [3-6]. Furthermore, some studies have indicated that LFP is a powerful free radical scavenger and exhibits strong antioxidant activity $[7,8]$, which suggest its use as a readily accessible source of natural antioxidants and/or a possible supplement in the food or pharmaceutical industry $[2,6]$.

Extraction yields of phenolics from plant tissues depend on the various extraction conditions [2]. Most phenolics present in plant tissues are soluble in polar solvents and can be extracted using methanol containing small amount of hydrochloric or formic acid $[3,9,10]$. The low $\mathrm{pH}$ value of the extraction solution can prevent the oxidation of phenolics, while the use of low temperatures may preserve anthocyanin stability $[2,11]$. Thus, an investigation of the efficient extraction of phenolics from LFP requires evaluation under various temperatures and solvent $\mathrm{pH}$ values.

Anthocyanins are the major phenolics present in LFP. The major anthocyanins from LFP tissues were identified as epicatechin, proanthocyanidin B4 and proanthocyanidin B2 [2, 10]. Anthocyanins show good antioxidant ability [7], but they are relatively unstable [9]. As the stability of litchi anthocyanins is dependent on various factors, such as $\mathrm{pH}$ value and temperature [12], the antioxidant ability of the litchi anthocyanins under the conditions of various temperatures and $\mathrm{pH}$ values also needs further evaluation.

The objective of this study was to examine the effects of various extraction temperatures and $\mathrm{pH}$ values on the extraction yield of phenolics from LFP and then evaluate total antioxidant ability and scavenging activities towards $\alpha, \alpha$-diphenyl- $\beta$-picrylhydrazy (DPPH) and hydroxyl radicals and superoxide anion of the extracted litchi anthocyanins under various temperatures and $\mathrm{pH}$ conditions. The study will help improve extraction of phenolics from litchi fruit pericarp and promote better utilization of the extracted litchi anthocyanins as antioxidants.

\section{Results and Discussion}

The extraction yield of phenolics from litchi fruit pericarp increased as the extraction temperature increased betwenn $30-80{ }^{\circ} \mathrm{C}$ (Figure 1), which suggested that litchi phenolics are relatively stable under high temperature conditions. Significant differences existed among 30, 40, 50 and $60{ }^{\circ} \mathrm{C}$ but did not appear between 60 and $70{ }^{\circ} \mathrm{C}$. Thus, in practice an extraction temperature of $60{ }^{\circ} \mathrm{C}$ could be used, basedon the combined effects of the good extraction yield of phenolics and the stability of litchi anthocyanins [12]. As shown in Figure 2, the extraction yield of phenolics from LFP increased as the $\mathrm{pH}$ values increased from 2 to 4 , but it decreased as the $\mathrm{pH}$ values higher than 4 were used, which indicated that the extraction $\mathrm{pH}$ value significantly affected the extraction yield compared with other factors. The increased extraction yield from LFP under the low $\mathrm{pH}$ conditions could be due to the inhibition of the enzymatic oxidation of phenolics and/or the maintenance of the extracted 
anthyocyanin stability $[2,12]$. As the extraction efficiency and anthocyanin stability depend largely on the combined effects caused by temperature and $\mathrm{pH}$ of extraction solution [11], further investigation to optimize the two extraction factors could be required.

Figure 1. The effects of various temperatures on extraction yield of phenolics from pericarp tissues of litchi fruit.

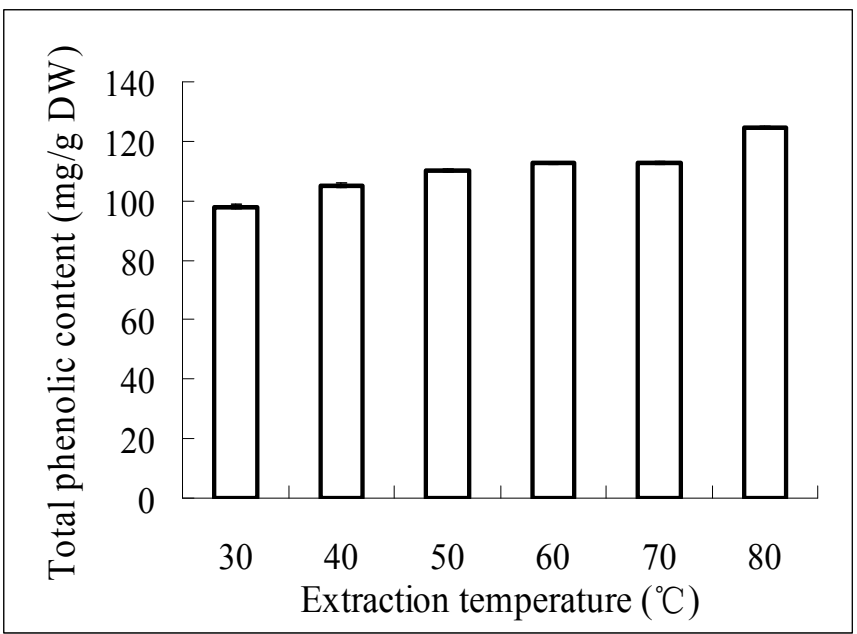

Figure 2. The effects of various $\mathrm{pH}$ values on extraction yield of phenolics from pericarp tissues of litchi fruit.

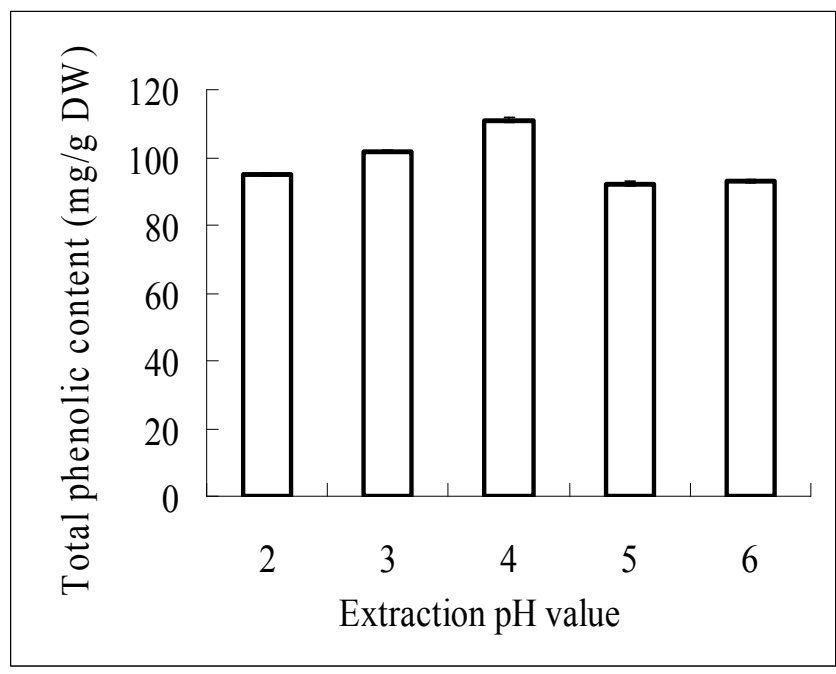

Litchi anthocyanins from fruit pericarp tissues were readily purified by Amberlite XAD-7 chromatography column [10], which gave a good purification of anthocyanins from plant tissues and had no effect on the anthocyanin compositions [13]. In this study, the partially purified litchi anthocyanins were used to further examine the effect of various temperatures and $\mathrm{pH}$ values on the antioxidant activity. As shown in Figure 3, the antioxidant activity of the litchi anthocyanins was enhanced with increasing temperature up to $45{ }^{\circ} \mathrm{C}$, but it decreased as the incubation time was extended to $60 \mathrm{~min}$. Furthermore, the antioxidant ability of litchi anthocyanins for $30 \mathrm{~min}$ at $45^{\circ} \mathrm{C}$ was 
significantly higher than that $55^{\circ} \mathrm{C}$. This study suggested that an appropriate temperature maintained a high antioxidant activity of litchi anthocyanins, which could be due to the combined effect of nonenzymatic reaction and anthocyanin stability [14].

Figure 3. The effects of various temperatures on total antioxidant ability (A) and scavenging activities of DPPH radical (B), hydroxyl radical (C) and superoxide anion (D) of litchi anthocyanin.

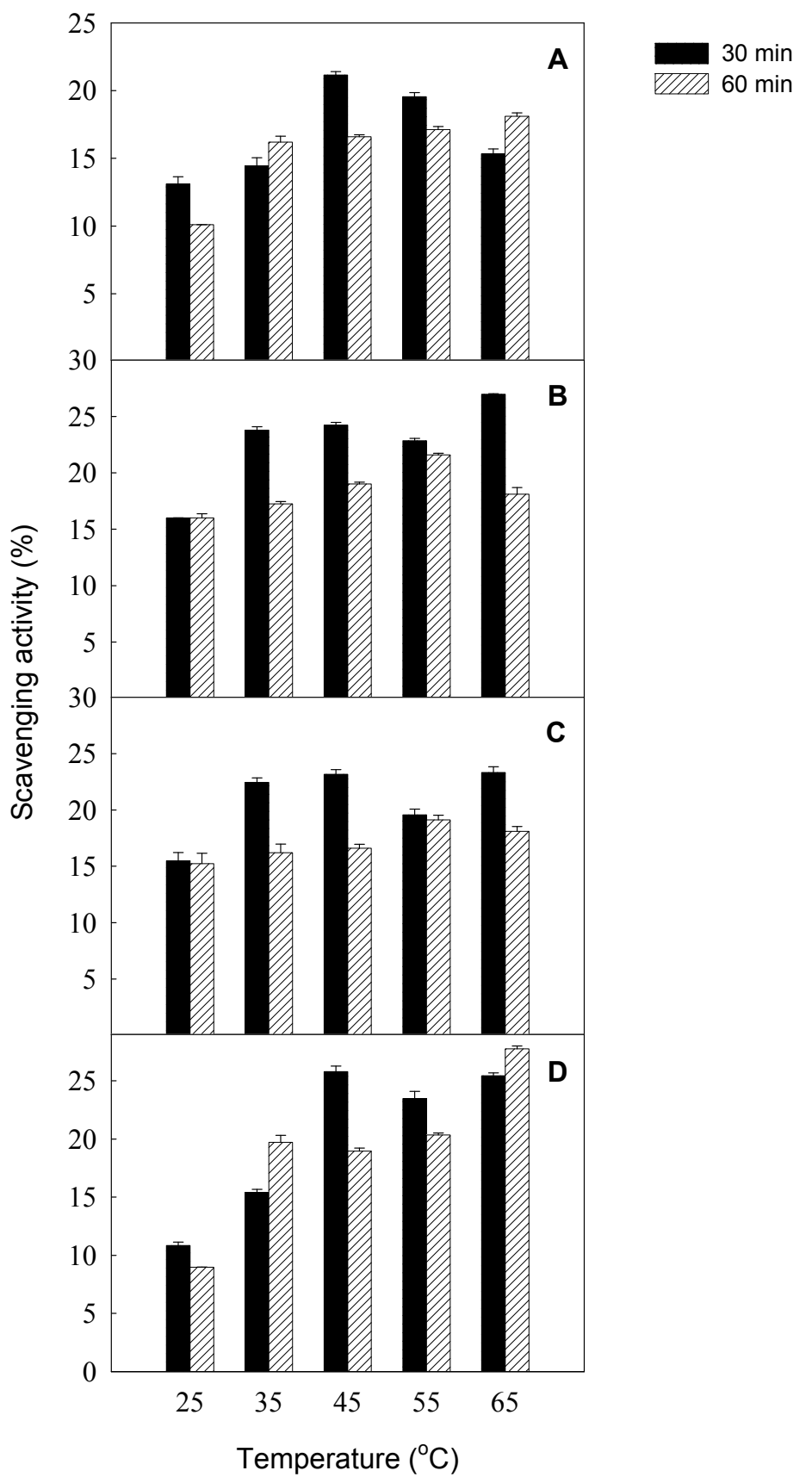


Figure 4. The effects of various $\mathrm{pH}$ values on total antioxidant ability (A) and scavenging activities of DPPH radical (B), hydroxyl radical (C) and superoxide anion (D) of litchi anthocyanin.

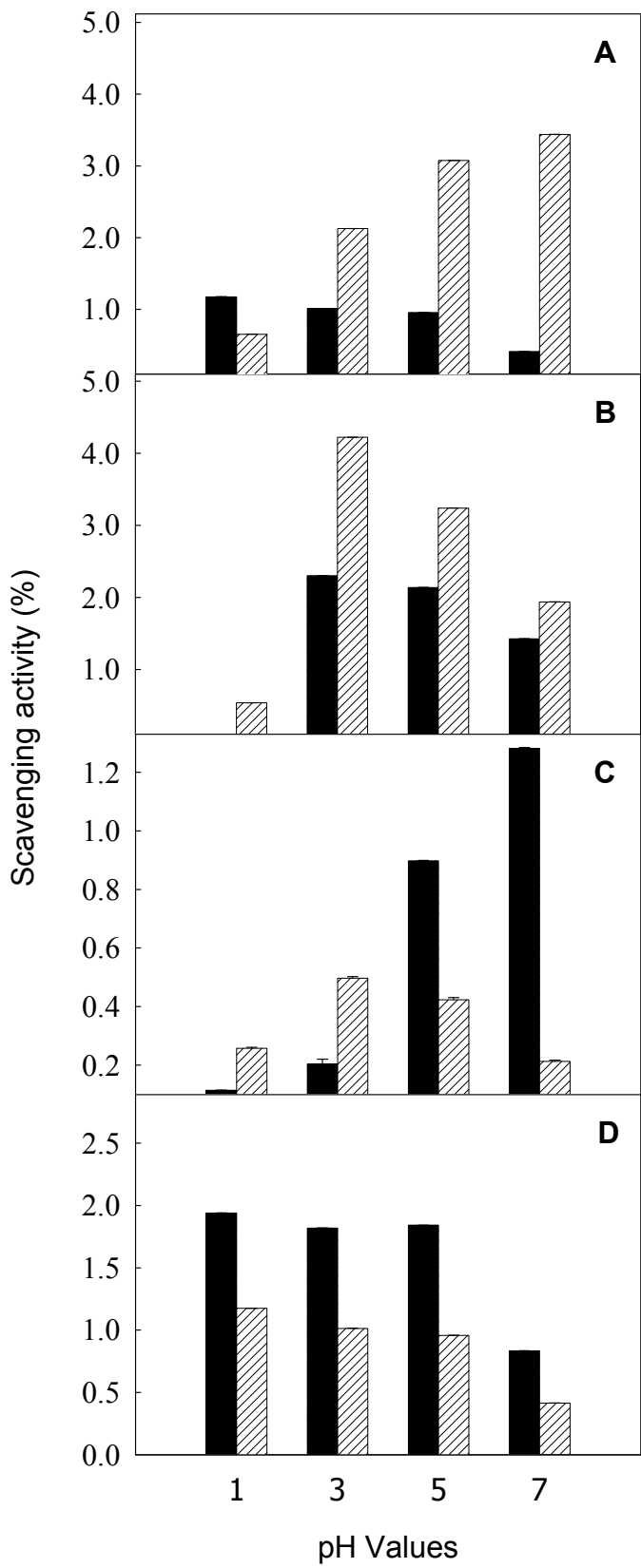

Figure 4 shows the effects of various $\mathrm{pH}$ values on total antioxidant ability and scavenging activities of litchi anthocyanins against DPPH and hydroxyl radical and superoxide anion. The superoxide anion scavenging activity of litchi anthocyanins was relatively stable at $\mathrm{pH} 1-5$. However, there was a higher scavenging DPPH radical activity at $\mathrm{pH} 3-5$, which was significant compared with $\mathrm{pH} 1$ or 7. In addition, the total antioxidant ability of litchi anthocyanins was enhanced as the incubation time was extended from 30 to $60 \mathrm{~min}$. Thus, $\mathrm{pH}$ values in the reaction medium significantly influenced the total antioxidant ability and scavenging activities of litchi anthocyanins against DPPH radicals, hydroxyl radical and superoxide anion, which could be due to the anthocyanin stability [12]. 


\section{Conclusions}

Various temperatures and $\mathrm{pH}$ significantly influenced the extraction yield of phenolics from LFP and the antioxidant activity of the extracted litchi anthocyanins. Application of $\mathrm{pH} 4.0$ exhibited the most efficient extraction while the extraction temperature of $60{ }^{\circ} \mathrm{C}$ could be used in terms of the combined effects of the extraction yield of phenolics and the stability of the extracted litchi anthocyanin. Furthermore, the temperatures from $45-60{ }^{\circ} \mathrm{C}$ and $\mathrm{pH}$ values from 3 to 4 exhibited a relatively high antioxidant activity. As the extraction efficiency and the antioxidant activity of the extracted litchi anthocyanins depend largely on the combined effects of temperature and $\mathrm{pH}[11,14]$, further investigation to evaluate the two extraction factors by use of the artificial neural network could be required.

\section{Experimental Section}

\subsection{Plant materials}

Fresh fruits of litchi (Litchi chinensis Sonn.) cv. Feizixiao were obtained from a commercial market in Guangzhou. Fruits were selected for uniformity and size and bruised or diseased fruits were then discarded. LFP tissues were collected, then dried and finally stored at $-18{ }^{\circ} \mathrm{C}$ for the following experiments.

\subsection{Experiment 1: Effects of various temperatures and $p H$ values on extraction yield of phenolics from $L F P$}

In our previous experiments, the use of $60 \%$ ethanol for an extraction time of $3 \mathrm{~h}$ exhibited the highest phenolic content from LFP. Thus, the extraction conditions were used to examine the effects of various temperatures and $\mathrm{pH}$ values on the extraction yield in this study. The dried LFP samples $(5 \mathrm{~g})$ were extracted for $3 \mathrm{~h}$ by stirring with $60 \%(\mathrm{v} / \mathrm{v})$ ethanol $(100 \mathrm{~mL})$ at $30,40,50,60,70$ or $80{ }^{\circ} \mathrm{C}$ and $\mathrm{pH} 7$, or $\mathrm{pH} 2,3,4,5$ or 6 adjusted by a diluted $\mathrm{HCl}$ solution and room temperature $\left(25^{\circ} \mathrm{C}\right)$. The homogenate was filtered through Whatman No. 1 filter paper under vacuum, collected, concentrated and then dried by a rotary evaporator under vacuum at $50{ }^{\circ} \mathrm{C}$. The dried filtrate was re-dissolved in $60 \%(\mathrm{v} / \mathrm{v})$ ethanol and then used for the analysis of total phenolic content. Total phenolic content was estimated with Folin-Ciocalteu reagent by the method of Singleton and Rossi [15], using gallic acid as a standard. Results were expressed as micrograms of gallic acid equivalents (GAE) per gram on dry weight (DW) basis.

\subsection{Experiment 2: Effects of temperatures and $p H$ values on antioxidant activity of the extracted litchi anthocyanin}

Litchi anthocyanin was extracted by the method of Zhang et al. [12]. The dried LFP tissues (50 g) were added to $1.5 \mathrm{M} \mathrm{HCl}$ solution in $95 \%$ ethanol $(1 \mathrm{~L})$ and then kept at $4{ }^{\circ} \mathrm{C}$ overnight. The extract solution was filtered through Whatman No. 1 paper and the filtrate was then collected as the crude litchi anthocyanin. The crude litchi anthocyanin was concentrated using a rotary evaporator under vacuum at $40{ }^{\circ} \mathrm{C}$ and purified by the method of Norbaek and Kondo [16]. The concentrated 
anthocyanin was loaded into Amberlite XAD-7 column $(1.5 \times 20 \mathrm{~cm})$ and then eluted with acetonitrile-trifloroacetic acid- $\mathrm{H}_{2} \mathrm{O}(200 \mathrm{~mL}, 50: 0.5: 49.5, \mathrm{v} / \mathrm{v} / \mathrm{v})$ [17]. The largest anthocyanin fraction was collected and lyophilized. The lyophilized anthocyanin was dissolved in a small amount of methanol and then used to examine the effects of temperatures and $\mathrm{pH}$ values on the antioxidant activity. The anthocyanin content was determined using a Unic UV-2802 spectrophotometer at 535 $\mathrm{nm}$. Litchi anthocyanin solution $(1 \mathrm{~mL})$ at $300 \mu \mathrm{g} / \mathrm{mL}$ was incubated at $25,35,45,55$ and $65{ }^{\circ} \mathrm{C}$ and pH 4 for 30 or $60 \mathrm{~min}$ in water baths, whereas the anthocyanin solution $(0.1 \mathrm{ml})$ was mixed with $0.9 \mathrm{ml}$ of $0.1 \mathrm{M}$ Tris- $\mathrm{HCl}$ buffer solution at $\mathrm{pH} 1,3,5$ or 7 and then incubated for 10 or $30 \mathrm{~min}$ at $25^{\circ} \mathrm{C}$, prior to the measurements of total antioxidant ability and scavenging activities of DPPH radical, hydroxyl radical and superoxide anion. Aliquots of the mixture solution were used for the following measurements.

\subsection{Total antioxidant activity}

Linoleic acid solution was prepared according to the method of Surrey [18]. Total antioxidant activity of litchi anthocyanin was determined by the method of Orak [19]. The mixture solution ( $1 \mathrm{~mL})$ mentioned above was added to linoleic acid solution $(5.0 \mathrm{~mL}, 6 \mathrm{mg} / \mathrm{mL}$ in $99 \%$ methanol) and then incubated for $10 \mathrm{~min}$ at $37{ }^{\circ} \mathrm{C}$. A $0.1-\mathrm{mL}$ aliquot of the mixture solution was added to $75 \%$ ethanol (4.7 $\mathrm{mL}), 0.1 \mathrm{M}$ ammonium thiocyanate $(0.1 \mathrm{~mL})$ and $20 \mathrm{mM}$ ferrous chloride $(0.1 \mathrm{~mL})$ in $3.5 \% \mathrm{HCl}$ solution. The reaction was then allowed for $5 \mathrm{~min}$ at $30{ }^{\circ} \mathrm{C}$ in dark. The absorbance was measured at $500 \mathrm{~nm}$. Total antioxidant activity was expressed as a percentage of lipid peroxidation value and calculated as the inhibition percentage $=\left(\mathrm{OD}_{0}-\mathrm{OD}_{1}\right) \times 100 / \mathrm{OD}_{0}$, where $\mathrm{OD}_{0}$ was the absorbance of the control sample without litchi anthocyanins and $\mathrm{OD}_{1}$ was the absorbance of the litchi anthocyanin sample.

\subsection{Scavenging activity against DPPH radical}

DPPH radical scavenging activity of litchi anthocyanins was evaluated by the method of Yamaguchi et al. [20]. Briefly, the mixture solution $(0.1 \mathrm{~mL})$ mentioned above was mixed with $0.1 \mathrm{M}$ Tris-HCl buffer $(0.5 \mathrm{~mL}, \mathrm{pH} 7.4)$ and $0.1 \mathrm{mM}$ DPPH in methanol $(0.4 \mathrm{~mL})$ solution. The reaction was allowed to proceed for $20 \mathrm{~min}$ at $30{ }^{\circ} \mathrm{C}$ in dark. Distilled water instead of litchi anthocyanin solution was used as the control. The scavenging activity of litchi anthocyanins against DPPH radicals was expressed as the inhibition percentage $=\left(\mathrm{OD}_{0}-\mathrm{OD}_{1}\right) \times 100 / \mathrm{OD}_{0}$, where $\mathrm{OD}_{0}$ was the absorbance of the control while $\mathrm{OD}_{1}$ was the absorbance of litchi anthocyanin sample.

\subsection{Scavenging activity against hydroxyl radical}

The assay of the hydroxyl radical scavenging activity of litchi anthocyanins was conducted in the $\mathrm{Fe}^{2+}$-EDTA- $\mathrm{H}_{2} \mathrm{O}_{2}$-deoxyribose systems [21]. Briefly, the mixture solution $(0.1 \mathrm{~mL})$ mentioned above was mixed with the reaction solution $(0.9 \mathrm{~mL})$ containing $0.1 \mathrm{mM} \mathrm{Fe}\left(\mathrm{SO}_{4}\right), 0.1 \mathrm{mM}$ EDTA and 1.75 $\mathrm{mM}$ 2-deoxyribose in $0.2 \mathrm{M}$ phosphate buffer ( $\mathrm{pH} 7.4)$. Then, $1.0 \mathrm{mM}$ ascorbic acid $(0.1 \mathrm{~mL})$ and 0.01 $\mathrm{M} \mathrm{H}_{2} \mathrm{O}_{2}(0.1 \mathrm{~mL})$ were respectively added to the reaction mixture and incubated for $10 \mathrm{~min}$ at $37^{\circ} \mathrm{C}$. Finally, $1 \%$ thiobarbituric acid $(0.5 \mathrm{~mL})$ and $2.8 \%$ tricholroacetic acid $(1.0 \mathrm{~mL})$ were added, mixed, 
and then boiled for $10 \mathrm{~min}$. The absorbance was measured at $532 \mathrm{~nm}$ and the scavenging activity of hydroxyl radical was then calculated as the percentage against the deoxyribose degradation.

\subsection{Scavenging activity against superoxide anion}

Superoxide anion scavenging activity was assayed by the method of Duan et al. [7]. Briefly, the mixture solution $(0.1 \mathrm{~mL})$ mentioned above was added to the reaction solution $(1 \mathrm{~mL})$ containing 50 $\mu \mathrm{M}$ riboflavin, $200 \mu \mathrm{M}$ EDTA, $0.5 \mathrm{mM}$ nitro blue tetrazolium and $20 \mathrm{mM}$ methionine in $0.1 \mathrm{M}$ phosphate buffer ( $\mathrm{pH}$ 7.4). The mixture solution was exposed to two $30 \mathrm{~W}$ fluorescent lamps for 20 min. The absorbance was measured at $560 \mathrm{~nm}$ and then calculated as the percentage of superoxide anion scavenging activity.

\subsection{Statistical analysis}

All analyses were performed in triplicate. Each value was the mean of three replicate determinations and the vertical bar indicated the standard error where it exceeded the symbol size. One-way analysis of variance (ANOVA) was carried out to test any significant difference between the means. Differences between the means at the $5 \%$ level were considered to be significant.

\section{Acknowledgements}

This work was supported by the National Natural Science Foundation of China (Grant No. 30425040 and U0631004) and Guangdong Provincial Natural Science Foundation (No. 06200670).

\section{References}

1. Jiang, Y.M.; Wang, Y.; Song, L.L.; Liu, H.; Lichter, A.; Kerdchoechuen, O.; Joyce, D.C.; Shi, J. Production and Postharvest Characteristics and Technology of Litchi Fruit: an Overview. Aust. J. Exp. Agric. 2006, 6, 1541-1556.

2. Li, J.R.; Jiang, Y.M. Litchi Flavonoids: Isolation, Identification and Biological Activity. Molecules 2007, 12, 745-758.

3. Cook, N.C.; Samman, S. Review: Flavonoids - Chemistry, Metabolism, Cardioprotective Effects, and Dietary Sources. J. Nutr. Biochem. 1996, 7, 66-76.

4. Lyons, W.P.M.; Samman, S. Flavonoids: Dietary Perspectives and Health Benefits. Nutr. Soc. Aust. 1997, 21, 106-114.

5. Yao, L.H.; Jiang, Y.M.; Shi, J.; Tomás-Barberán, F.A.; Datta, N.; Singanusong, R.; Chen, S.S. Flavonoids in Food and Their Health Benefits. Plant Foods Human Nutr. 2004, 59, 113-122.

6. Zhao, M.; Yang, B.; Wang, J.S.; Liu, Y.; Yu, L.M.; Jiang, Y.M. Immunomodulatory and Anticancer Activities of Flavonoids Extracted from Litchi (Litchi chinensis Sonn.) Pericarp. Inter. Immunopharmacol. 2007, 7, 162-166.

7. Duan, X.W.; Jiang, Y.M.; Su, X.G.; Zhang, Z.Q.; Shi, J. Antioxidant Property of Anthocyanins Extracted from Litchi (Litchi chinenesis Sonn.) Fruit Pericarp Tissues in Relation to Their Role in the Pericarp Browning. Food Chem. 2007, 101, 1382-1388. 
8. Zhao, M.M.; Yang, B.; Wang, J.S.; Li, B.Z.; Jiang, Y.M. Identification of the Major Flavonoids from Pericarp Tissues Of Lychee Fruit in Relation to Their Antioxidant Activities. Food Chem. 2006, 98, 737-742.

9. Zhang D.L.; Grigor J.M.; Quantick P.C. Changes in Phenolic Compounds in Litchi (Litchi chinensis Sonn.) Fruit during Postharvest Storage. Postharv. Biol. Technol. 2000, 19, 165-172.

10. Zhang, Z.Q.; Pang, X.Q.; Yang C.; Ji, Z.L.; Jiang, Y.M. Purification and Structure Analysis of Anthocyanins from Litchi Pericarp. Food Chem. 2004, 84, 601-604.

11. Laleh, G.H.; Frydoonfar, H.; Heidary, R.; Jameei, R.; Zare, S. The Effect of Light, Temperature, PH and Species on Stability of Anthocyanins Pigments in Four Berberi Species. J. Nutr. 2006, 5 , 90-92.

12. Zhang, Z.Q.; Pang, X.Q.; Yang, C.; Ji, Z.L.; Jiang, Y.M. Role of Anthocyanins Degradation in Litchi Pericarp Browning. Food Chem. 2001, 75, 217-221.

13. Liu, X.M.; Xiao, G.S.; Chen, W.D.; Xu, Y.J.; Wu, J.J. Quantification and Purification of Mulberry Anthocyanins with Macroporous Resins. J. Biomed. Biotechnol. 2004, 5, 326-331.

14. Reyes, L.F.; Cisneros-Zevallos, L. Degradation Kinetics and Colour of Anthocyanins in Aqueous Extracts of Purple and Red Flesh Potatoes (Solanum tuberosum L.). Food Chem. 2007, 100, 885894.

15. Singleton, V.L.; Rossi, J.A. Colorimetry of Total Phenolics with PhosphomolybdicHosphotungstic Acid Reagents. Amer. J. Enol. Viticult. 1965, 16, 144-158.

16. Norbaek, R.; Kondo, T. Further Anthocyanins from Flowers of Crocus antalyensis (Iridecae). Phytochemistry 1999, 50, 325-328.

17. Kähkönen, M.P.; Heinämäki, J.; Olliainen, V.; Heinonen, M. Berry Anthocyanins Isolation Identification and Antioxidant Activities. J. Sci. Food Agric. 2003, 83, 1403-1411.

18. Surrey, K. Spectrophotometric Method for Determination of Lipoxidase Activity. Plant Physiol. 1964, 39, 65-70.

19. Orak, H.H. Total Antioxidant Activities, Phonolics, Anthocyanins, Polyphonoloxidase Activities and Its Correlation of Some Important red Wine Grape Varieties Which are Grown In Turkey. LWT-Food Sci. Technol. 2006, 9, 1-7.

20. Yamaguchi, T.; Takamura, H.; Matoba, T.; Terao, J. HPLC Method for Evaluation of the Free Radical Scavenging Activity of Foods by Using 1,1-Diphenyl-2-Picrylhydrazyl. Biosci. Biotechnol. Biochem. 1998, 62, 1201-1204.

21. Ghiselli, A.; Nardini, M.; Baldi, A.; Scaccini, C. Antioxidant Activity of Difference Phenolic Fractions Separated from an Italian Red Wine. J. Agric. Food Chem. 1998, 46, 361-367.

Sample availability: Available from the authors.

(C) 2008 by the authors; licensee Molecular Diversity Preservation International, Basel, Switzerland. This article is an open-access article distributed under the terms and conditions of the Creative Commons Attribution license (http://creativecommons.org/licenses/by/3.0/). 